María Luisa Pérez Bernardo

Universidad de Dallas

\title{
INFANCIAS DESGRACIADAS EN PRIMERA MEMORIA DE ANA MARÍA MATUTE
}

Palabras clave: Ana María Matute, infancia, adultos, hipocresía

\section{Introducción}

La década de 1950 vio por fin el resurgir brillante de las letras españolas, después de unos años intentando asumir las consecuencias de la guerra y superar la ruptura en la evolución literaria que ésta había provocado. Durante esta época se asiste a unos intentos de renovación, gracias a unas serie de determinadas circunstancias históricas que la favorecen o condicionan: la progresiva incorporación de España a la órbita internacional tras el anterior aislamiento; una tímida liberalización intelectual; la entrada del turismo extranjero y la posibilidad de viajar fuera del país y de conocer una literatura diferente.

Surge una nueva generación, la de los «niños de la guerra» o del «medio siglo», con lo que a partir de entonces jóvenes y menos jóvenes trabajarían juntos, enriqueciendo, diversificando nuestra novelística. Se trata ahora de quienes eran niños al comienzo de la guerra civil, cuyos sucesos padecieron, y que, mediando el siglo, hacen acto de presencia con su específico talante, nunca unánime (Martínez Cachero, 1981: 310). Para todos ellos, la contienda y la posguerra, más los acontecimientos mundiales coincidentes con esta última fueron algo así como el hecho generacional que actuaba de forma revulsiva. Debido a esto, eligieron una actitud y cargaron deliberadamente de intención social sus narraciones. Aunque ya en la década de los cuarenta habían aparecido algunas obras que podían incluirse genéricamente en el realismo histórico, sólo a partir de 1954 se perfila como una corriente dinámica y coherente. Este es el año de publicación de cuatro novelas de Juan Goytisolo, Jesús Fernández Santos, Ignacio Aldecoa y Ana María Matute, respectivamente, que, al coincidir en líneas generales, en torno a ciertos postulados éticos y estéticos, darán a esta generación un carácter de movimiento colectivo de que hasta entonces había carecido (Curutchet, 1964: 59).

La novela que siguió este grupo supuso un renacimiento caracterizado por la tendencia a devolver el contenido humano y realista, psicológico y social que había perdido en los años deshumanizadores, no como vuelta al realismo del siglo pasado, sino incorporando en el estilo algunas de las conquistas hechas por la sensibilidad contemporánea. A partir de entonces, el realismo social fue la fuerza dominante, siendo igualmente notable en ellos una oscilación entre el lirismo subjetivo y la objetividad despersonalizada. Este contenido ético de solidaridad humana impone unas exigencias temáticas y estéticas determinadas: atención prioritaria a los problemas del hombre dentro del contexto social y político de la época, búsqueda de un lenguaje sencillo, sin ornamentos, un tono predominantemente narrativo, que en ocasiones, deriva hacia el prosaísmo, en definitiva, una es- 
tética de la sobriedad. Además, surge una literatura de oposición al régimen, bien porque los autores buscaron la crítica, bien porque, al actuar con mayor libertad y en sintonía con los aires del momento, presenta una realidad que entra en conflicto con la propaganda oficial franquista.

Ana María Matute es una de las protagonistas de esta generación de medio siglo. La escritora nació en Barcelona en 1926, y se dio a conocer en el mundo de la literatura con Los Abel (1948), obra inspirada en la historia bíblica de los hijos de Adán y Eva, en la cual reflejó la atmósfera social posterior a la guerra civil española desde el punto de vista de la percepción infantil. Con Los Abel se reveló como prometedora novelista, con tan sólo veintiún años, al quedar finalista del premio Nadal en 1947, precisamente el mismo año que triunfó Miguel Delibes con La sombra del ciprés es alargada.

$\mathrm{Al}$ adentrarnos al mundo novelesco de Matute, se observa como los temas fundamentales de sus obras son los niños, la muerte, la huida, el amor-odio y la guerra, tomando ésta como fondo o como asunto principal, reflejando el sufrimiento humano debido al abocamiento de pasiones como la envidia, el aislamiento y la venganza. Las novelas de la escritora catalana no están exentas de compromiso social, si bien es cierto que no se adscriben explícitamente a ninguna ideología política. Partiendo de la visión realista imperante en la literatura de su tiempo, logró desarrollar un estilo personal que se adentró en lo imaginativo y configuró un mundo lírico y sensorial, emocional y delicado. El núcleo de la inmensa galería de personajes de la obra de Ana María Matute lo componen personas hurañas, mutiladas por los vicios de la época, caracterizados por su mediocridad y también por su crueldad. Los caracteres pueden ser triviales y caricaturescos, pero a la escritora le duele profundamente el destino de los desheredados, en particular cuando se trata de los niños. Y es justamente el estudio de las infancias desgraciadas de Matute el tema del presente ensayo. En concreto, voy a mostrar como Primera memoria se centra en el mundo de los niños, en un universo donde al final los más pequeños serán contaminados por lo cruel, absurdo y grotesco de los adultos. Matia, la protagonista se refugia en el aislamiento emocional, tiene conciencia de las injusticias sociales y sueña con la libertad, debatiéndose en un ambiente represivo. De hecho, todo en la novela reflejará la frustración de la joven, al no poder cambiar el ambiente de hipocresía y falsedad que vivía en su propia familia, teniendo que sucumbir a él.

\section{Infancias desgraciadas en la obra de Matute}

El tema de la infancia y la adolescencia reaparece constantemente en las novelas de posguerra, y llegará a convertirse en algunos casos en rasgo distintivo de uno o de varios autores de esta generación: Juan Goytisolo, Miguel Delibes y Rafael Sánchez Ferlosio entre otros. En las obras se describe el drama de los niños a quienes la guerra despojó de su candor y su inocencia llevándoles a imitar los juegos de los mayores. También la narrativa de Matute trata a menudo del mundo de la infancia, sus novelas reflejan muchachos desde un punto de vista abierto a la complejidad múltiple de la realidad. Más de una vez ha dado muestras de fascinación por una época que, a su juicio, nos marca para siempre: «El niño no es un proyecto de hombre, sino que el hombre es lo que queda del niño que 
fue» ${ }^{1}$. En otra ocasión escribió que: «La infancia es una edad total, una vida cerrada y entera» y que: «El niño está siempre solo, es quizás el ser más solo de la creación» (Matute, 1961: 133). Incluso en una entrevista concedida al diario madrileño Ya, la propia autora resume sus ideas acerca del papel de la niñez en la vida adulta: «Es un gran error decir que el niño es un proyecto del hombre; yo pienso que es al revés: que el hombre es un trocito de niño que fue, porque a lo largo de la vida si cambiamos, siempre es para empeorar»².

Efectivamente, la escritora barcelonesa tras el nacimiento de su hijo Juan Pablo en 1954, se puso en estrecho contacto con los problemas de la infancia, que tanto le interesaban como mujer y que tanto le han ocupado como escritora. Cuando Juan Pablo tenía dos años, publicó el primero de sus cuentos infantiles, género que no ha abandonado desde entonces y que le ha proporcionado varios reconocimientos por su dedicación a la Literatura Juvenil: el Premio Nacional de Literatura Infantil en 1964 con la novela El polizón de Ulises y en 1984 volvió a recibir otro galardón de gran envergadura con la obra Sólo un pie descalzo. Además, tiene una amplia obra dedicada a los más pequeños: El país de la pizarra (1956), El saltamontes verde (1961), El aprendiz (1961) y El carnavalito (1961).

A este respecto, se ha dicho repetidas veces que su obra representa «un mundo novelesco fabricado de jóvenes determinados a quedarse niños y adultos tozudamente cerrados a la vida de su ser original» (Valis, 1982: 409). Unas veces estas novelas para los más pequeños se enmarcan en un ambiente de magia y fantasía, en un bosque recóndito donde existen gnomos y hadas, otras se abandona el espacio de la Edad Media para situarse en uno real, volviendo a la novela de corte realista, sobre todo cuando se ubica en la posguerra.

Efectivamente, uno de los aspectos que más destaca es el hecho de que los personajes son niños precozmente crecidos para el sufrimiento, o adolescentes que ostentan una añoranza imposible de una niñez perdida. Nannete Pascal en el estudio que hace sobre la novelística de Ana María Matute, reconoce que la perspectiva tradicional de la infancia, de la edad ingenua, feliz y despreocupada, está ausente en su obra, más bien predomina la niñez precoz, egoísta, cruel, esencialmente triste y solitaria:

Matute no idealiza a sus niños. Muy al contrario, expone, con resultados, en ocasiones, inesperados y grotescos (como en sus cuentos), la maldad inconsciente, la inocencia perversa del niño. Los personajes niños de Matute son idealistas y soñadores pero, también crueles y propensos a la violencia. (Pascal, 1980: 7)

También José Más ha indicado que en la novelística de la escritora catalana aparece el tema del desgarramiento interno de los personajes adultos que han crecido físicamente, pero que conservan en el interior el alma del niño que fueron o que les hubiera gustado ser: «Así pues, niño y adulto coexisten en un mismo individuo como siameses que, fatalmente unidos, tirarán cada uno de su lado hasta que se descoyuntaran o aniquilasen» (Más, 1988: 31).

\footnotetext{
Ana María Matute. El Mundo. 25 de mayo de 1990, 1.

2 Ana María Matute. Ya. 6 de agosto de 1972, 3.
} 
En este sentido, la visión que tiene Matute de los más jóvenes no está cargada de nostalgia, como ocurre en la obra de Miguel Delibes El camino (1950), ya que para la escritora, la infancia no es una edad de oro, feliz y sin complicaciones, más bien, es una etapa conflictiva, que refleja la entrada inevitable al ambiente cruel de los adultos. Muchos de los pequeños padecen la pérdida de uno de los miembros de la familia, son normalmente huérfanos, viven en un mundo de miedo e incertidumbre, y en la mayor parte de los casos, sufren la hipocresía de los más mayores. Además de la orfandad, los niños experimentan las carencias afectivas, la añoranza del padre o la madre siempre ausente, incluso el silencio de los que los rodean. En otros casos, el mundo de la infancia está despoblado de juegos y de ensueños, es la ventana a la amargura de la vida. En el complejo mundo de los jóvenes encontraremos tanto dramatismo como poesía, tanto tristeza como generosidad; hallaremos, sobre todo, la ingenua sinceridad de los inocentes, siempre amenazados por una realidad que les es ajena y que los atenaza con su garra implacable: los adultos, habitantes de esa realidad tienen hecho un universo a la medida del egoísmo y de su insolidaridad y han levantado un muro de incomprensión que genera desdichas, perdiendo definitivamente su autenticidad.

Efectivamente, en Historias de Artámila (1961) y otras obras publicadas exclusivamente para adultos, aparecen personajes infantiles cuyos sueños y fantasías desaparecen tras el paso del tiempo y las circunstancias, perfilándose así un entorno trágico de los seres desilusionados y solitarios. Los críticos han comentado que este tipo de personajes lo sacó de sus vivencias personales, cuando Ana María Matute a los ocho años, con motivo de una enfermedad, fue enviada a la casa de sus abuelos en Mansilla de la Sierra (La Rioja). En este pueblo se sitúa la acción de la mayoría de sus novelas: Fiesta al Noroeste, Los hijos muertos, El río, Historias de Artámila y El tiempo. En Mansilla, Ana María acudió a la escuela con otros niños, muchachos sin infancia, nacidos para morir. También conoció el mundo corrupto de los adultos, de hombres resignados con su soledad y miseria, y por supuesto, a aquellos que sustentaban el poder: los ricos y avariciosos, responsables de ese lamentable estado de las cosas.

\section{Primera memoria}

Primera memoria (1959) es la entrega inicial de una trilogía Los mercaderes completada con Los soldados lloran de noche (1964) y La trampa (1969). Primera memoria está narrada en primera persona, desde el punto de vista de Matia, interviniendo en los acontecimientos y asumiendo una función de protagonista, y sobre todo, explorando la progresiva revelación del mundo de los adultos, con todas sus contradicciones, sus engaños y su falsedad. Esta forma de narrar da la impresión de reproducir los pensamientos como llegan a la mente de la joven de forma desorganizada y confusa, mezclándose en ella, las imágenes, sensaciones, sentimientos e ideas expuestas sin lógica y con distorsiones temporales. ${ }^{3}$

\footnotetext{
Margaret Jones ha comentado sobre el estilo: «These random thoughts are superimposed on the narration, with the cinematographic effect of a montage of memory-images. Thus, by juxtaposition of past and present, the author effectively recreates her character's shifting point of view: an "objective" narration of adolescence in the form of the memoria; random comments and evocations, set off by parentheses, expressed by the adolescent Matia; and finally, the present tense comments of the older Matia, who is writing the story» (Jones, 1993: 23).
} 
Como bien comenta José Más, Primera memoria (1959) se centra en la indagación apasionada del mundo de la adolescencia, donde se entrecruzan añoranzas, sueños y temores (Más, 1988: 19). En cualquier caso, lo importante es el hecho de que la joven se halla en un momento crucial de su vida, esto es, en la frontera entre ser niña y comenzar a ser considerada mujer. La novela se construye como un Bildungsroman de Matia, ya que a lo largo del relato, la protagonista va desarrollando su personalidad, que va desde la niñez, como una etapa de inocencia e ingenuidad, hasta la adolescencia, cuando poco a poco se va contaminando del ambiente hostil que la rodea. ${ }^{4}$ En este periodo se va modelando su carácter, su concepción del mundo y del destino, en contacto con la sociedad de la época, que le sirve de aprendizaje a través de las más variadas experiencias. ${ }^{5}$ Se trata de un medio de iniciación a la vida, de ruptura con el mundo anterior de la adolescencia para liberar y desarrollar las potencialidades de la personalidad y crear su propio esquema de valores y proyecto de la vida.

La acción se sitúa en la isla de Mallorca en los días de guerra. Aunque no exista la contienda bélica en este territorio, sí que aparecen ecos de crueldad, se muestra de forma fidedigna la vida de aquellos sectores de la sociedad española que sufrían la ofensiva. La isla es un reducto de paz soñado en la tempestad de la guerra, no obstante, la paz no es total, hallándose tensada por odios reprimidos. Efectivamente, se aprecia aquí la reelaboración del mito de Caín y Abel, aspecto este tan recurrente en la mayoría de las obras de la escritora barcelonesa, a través de los sucesos cruentos que ocurren en este lugar. De hecho, ya en el primer capítulo se presenta a José Taronjí, padre de Manuel, que fue víctima de la contienda, asesinado por las autoridades por sus ideas de izquierda. En este caso, este escenario no resulta en absoluto idílico; hay un paisaje grato, pero el entorno social está dominado siempre por la brutalidad de sus habitantes, describiéndosenos con todo detallismo las ejecuciones y muertes que se llevaron a cabo durante la contienda; incluso cómo algunos de ellos eran asesinados y despeñados por los acantilados de la playa. También, el conflicto de la lucha peninsular se repite a la escala infantil en la guerra de pandillas entre los niños de la isla, imitando al mundo de los mayores. A través de la conciencia de Matia, se nos muestra lo cruel de la situación y su oposición a estas peleas, diciendo:

Entre los árboles daban comienzo sus atroces peleas, persiguiéndose con saña mi primo, con el revólver o con la carabina, la mantenía lejos. Era una guerra sorda y ensoñada, cuyo sentido no estaba a mi alcance, pero que me desazonaba, no por el daño que pudieran hacerse, sino porque presentía en ella algo oscuro, que me estremecía. (Matute, 1959: 111-112)

\footnotetext{
Margaret Jones nos dice al respecto: «The main theme of the loss of childhood is framed by a plot designed to heighten this tragic sense of privation. Matute has chosen the fictional autobiography as an apt form for conveying Matia's bitterness and the sharp sense of nostalgia for the lost childhood» (Jones, 1993: 22).

5 Janet W. Díaz afirma que: «The transition from childhood to adulthood is a major theme, but by no means the only one, despite the fact that numerous critics (including Spanish, French and American commentators) have given it exclusive mention. This becomes more apparent when the novel is considered in relation to other parts of the trilogy» (Díaz, 1971: 134).
} 
Además de esta esfera de violencia, la muchacha enfatiza el ambiente de asfixia que se respiraba en su propia casa, reiterándose continuamente la sensación de aburrimiento y opresión, en contraste con la libertad que vivía antes de la guerra. También se revela la falta de comunicación, las trabas sociales a la que debían enfrentarse sus personajes y como las relaciones de los protagonistas se caracterizaban por su superficialidad y por la monotonía. De hecho, todo en la narración alude a una casa como una fortaleza, con grandes muros y vallas, para así impedir el contacto con el exterior, con la emancipación que los niños desean:

La calma, el silencio y una espera larga y exasperante en la que, de pronto, nos veíamos todos sumergidos, operaba también sobre nosotros. Nos aburríamos e inquietábamos alternativamente, como llenos de una lenta y acechante zozobra, presta a saltar en cualquier momento. Y empecé a conocer aquella casa, grande y extraña, con los muros de ocre y el tejado de alfar, su larga logia con balaustrada de piedra y el techo de madera, donde Borja y yo, de bruces en el suelo, manteníamos conversaciones siseantes. (Matute, 1959: 18)

Frente a estas tapias de piedra, que simbolizan la falta de libertad y la coacción, se muestran los paseos y escapadas de Matia a hurtadillas y sin previo consentimiento de la abuela, buscando así la independencia a través de esos pequeños viajes en la barca «Leontina». También la chica se dirige siempre hacia la huerta, la playa, incluso se asoma continuamente por la ventana, para así poder respirar el aire fresco del que carece la casa, diciendo:

Así, los dos, en la logia, que la abuela no le gustaba pisar, y que sólo veía a través de las ventanas abiertas, hallábamos el único refugio en la desesperante casa, siempre hollada por las pisadas macizas de la abuela, que olfateaba como un lebrel nuestras huidas al pueblo, al declive, a la ensenada de Santa Catalina, al Port. (Matute, 1959: 19)

Desde el principio, la escritora representa a través de la isla, un mundo que reproduce, en pequeño, las características de la realidad social de la época: ricos y pobres separados por las odiosas diferencias y en pugna unos contra otros. Por un lado están los que sustentan el poder y representan un falso orden, frente a los otros que tienen que acatarse a la ley, obedeciendo sumisamente a ésta, incluso cuando no están de acuerdo con esos principios. A través de la abuela Práxedes y la tía Emilia, se nos muestra la frivolidad y la insensibilidad de los representantes de la sociedad establecida y la desmitificación de los principios y valores que les servía de fundamento. De hecho, a través de la narración se reitera que la tía era el modelo femenino de la época; ya que lo único que hacía era tocar malamente el piano, y aunque su marido se encontraba luchando en la contienda, no se interesaba lo más absoluto por la situación, mostrándose el estado de apatía en que vivía:

Ni siquiera leía los periódicos y revistas de que se rodeaba amontonadamente: los ojeaba, distraída, y bien se notaba, si permanecía rato y rato con los ojos sobre una fotografía, que su pensamiento estaba lejos. Tenía los ojillos azules, con la córnea rosada, y no cesaba de 
espiar por las ventanas o de mirar hacia el patio por el hueco de las escaleras. (Matute, 1959: 64)

Parece como si Ana María Matute quisiera que el lector advierta que lo que está contando es la demostración de la conducta social propia de la posguerra; para probar esta tesis, el relato incurre en reiteraciones y subrayados, que sin duda, resultan excesivos. Así en el primo de Matia, Borja, se concentran todos los males atribuidos a la clase burguesa a la que pertenece, presentándonos las flaquezas, debilidades y mentiras del niño que se apropia del dinero de los otros, que usa la violencia para atemorizar a los más débiles, o que mantiene sus prejuicios sociales en contra de los muchachos más pobres del pueblo. Nanette Pascal ha señalado cómo Borja, aún siendo de la misma edad que su prima, muestra ser un personaje que: «Es el símbolo de la decadencia moral, aún más agudiza, es el símbolo de esa inocencia perversa de la niñez, del niño hipócrita que sigue las normas del mundo adulto» (Pascal, 1981: 73). De hecho, desde el inicio de la narración, Matia confiesa que el muchacho es un hipócrita, que disimula delante de su abuela, pero que en realidad, él es el único culpable de los robos, aunque nunca llegue a admitirlo.

Pero el texto, tal como lo ha advertido Rosa Isabel Galdona, insiste en recordarnos la lucha de Matia contra la realidad hostil que la rodea, concretada frecuentemente, en aislamiento, en búsqueda de paz interior que la aparta del mundo y de las maldades (Galdona, 2001: 207). La propia interioridad se vuelve, así, refugio y reconfortante. De hecho, la joven vive en un mundo de fantasía, de imaginación, frente al ambiente de caos, teñido de sangre y venganzas que se respira en el pueblo. La adolescente, infeliz, marioneta de la soledad, del desamor y la injusticia, huye del absurdo circundante sumergiéndose en un espacio fantástico. De esta manera, la muchacha quiere aferrarse a su muñeco Gorogó y a la figura de Peter Pan, el niño eterno, acudiendo siempre a ellos, cuando quiere olvidar el mundo de los adultos:

(Dentro del armario, estaba mi pequeño bagaje de memorias: el negro y retorcido hilo del teléfono, con su voz, como una sorprendente sangre sonora. Las manzanas del sobrado, la Isla de Nuna Jamás, con sus limpiezas de primavera)... Pero vivíamos en otra isla. Se veía, sí, que en la isla estábamos como perdidos, rodeados del pavor azul del mar y sobre todo, de silencio. Y no pasaban barcos por nuestras costas, nada se oía ni se veía: nada más que el respirar del mar. (Matute, 1959: 116)

En este sentido, la protagonista es una «chica rara» que se refugia en las lecturas de los cuentos de Andersen, tratando de volver a aquel paraíso feliz, donde todo era posible por fantástico e irreal que pareciese. Este aspecto ha sido observado por los críticos, en especial por Marisa Sotelo, que afirma que estos cuentos actúan en la novela como un punto de salida ante el mundo corrupto de los mayores: «Frente al discurso narrativo entreverado de la fantasía de las historias de hadas, la realidad evocada, acaba siendo teñida de amargo desencanto, desmiente o burla la fantasía de los mismos» (Sotelo, 1999: 176). En otros momentos, la lectura de Andersen se trasluce nítidamente en la comparación que 
establece Matía entre su sensación de soledad, tristeza, indefensión, falta de afecto y sus deseos de sentirse verdaderamente amada por alguien.

Además de alejarse del resto por medio de este mundo de ensoñación, la joven continuamente parece rebelarse contra la ideología de la tía y de la abuela. ${ }^{6}$ Se nos dice que quiere romper con el modelo de feminidad que se quería imponer en la época: el hecho de que al ser ya una adolescente, tenía que estar preocupada por su aspecto físico, pues según la tía: «La belleza, pues, era el único bien con que podía contar en la vida para un buen matrimonio» (Matute, 1959: 119). La abuela de Matia, lleva muchos años en observancia y en la enseñanza de este deber femenino. Como mujer experimentada, entiende que cultivar el físico de su nieta constituye el primer paso para hacer de ella «una señora respetable» y «una esposa admirable», insistiendo en ello de forma continua. También se la obligaba a estudiar ciertas materias consideradas apropiadas para el género femenino; como el saber unas nociones de francés, aprender bordado y ganchillo y un sólido conocimiento de protocolo social. Frente a este modelo, Matia se resiste, su propia descripción denota la imagen de una adolescente despreocupada por su belleza, con el pelo suelto y fumando, simbolizando de nuevo, el ansia de autonomía al que aspira, frente a la opresión de la época.

Ahora bien, la joven irá reconociendo a lo largo de la obra, una lección de desengaño, que le servirá de experiencia moral, de auto-conocimiento y de desarrollo espiritual. ${ }^{7}$ Se trata por tanto, de una ruptura con el mundo de la infancia, de la inocencia, cuando su primo Borja delate a su íntimo amigo, Manuel, el único espíritu noble que había conocido. De hecho, el último capítulo «El gallo blanco», simboliza así la traición, cuando Manuel es acusado injustamente por Borja de apropiarse del dinero de su abuela, logrando que el primero sea recluido en un reformatorio. Como bien indica su nombre, Manuel simboliza la figura de Cristo, que termina falsamente sacrificado por Borja $^{8}$. Matia que había colaborado con su primo, se da cuenta de que todo ha cambiado en su vida, que ha abandonado la infancia para entrar de forma trágica en el ambiente corrupto de los adultos, cuando en vez de defender a Manuel, escapó y le dejó solo ante la falsa acusación.

Al final, Matia, que había luchado denodadamente contra la hipocresía que se respiraba en la casa, termina cediendo a la presión externa, dándose cuenta de que llevaba todas las de perder en ese ambiente tan perverso, sin quedarle más remedio que some-

6 Guadalupe Cabedo afirma que: «Las autoras de posguerra desarrollaron un mecanismo de escape y al mismo tiempo de enfrentamiento, pues al no existir estas madres naturales, las protagonistas manifiestan su inconformismo contra sus madres sustitutas (tías, abuelas o hermanas mayores), con quienes no es forzoso que exista ese lazo de amor y admiración» (Cabedo, 2005: 58).

7 Marisa Sotelo Vázquez sostiene que: «El apego a la niñez y a la conciencia de que su huella condiciona la trayectoria posterior de los adultos explican algunos de los trazos de la personalidad literaria de Ana María Matute. Los niños no mueren nunca del todo, pero para la novelista, ir viviendo supone ir perdiendo inexorablemente la felicidad, al descubrir la falsedad, la mezquindad de la doblez que poco a poco agrietan la perfección del mundo infantil» (Sotelo Vázquez, 1999: 172).

8 Janet Díaz ha dicho al respecto: «Manuel, another important adolescent is in many ways Borja’s opposite, and in others, a Christ-like figure, wrongly accused and sacrificed. Betrayed by Borja and denied by Matia, Manuel is not martyred physically, but psychologically, his childhood irrevocably truncated» (Díaz, 1971: 134). 
terse a los dictámenes de la familia. La narración finaliza de forma desesperanzada, con la sensación de haber perdido la franqueza e inocencia de sus primeros años en la isla, desapareciendo las palomas, símbolo de la libertad, y sobre todo, teniendo que admitir su impotencia para luchar contra esa sociedad corrupta: ${ }^{9}$

Sólo sé que al alba, me desperté. Que como el primer día de mi llegada a la isla, la luz gris perlada del amanecer acuchillaba las persianas verdes de mi ventana. Tenía los ojos abiertos. Por primera vez, no había soñado nada. Algo había en la habitación como un eleteante huir de palomas. Entonces, supe que en algún momento de la tarde, con la luz muriendo, había vuelto allí, que quedé presa en aquel viento, junto a la verja pintada de verde, cerrada con llave, de San Major. (Matute, 1959: 242-243)

\section{Conclusión}

El tema de la infancia atormentada y solitaria, aprisionada en un mundo adulto incomprensible, es un tema recurrente en la narrativa de Ana María Matute. Los personajes infantiles de estas obras se debaten sin gran fortuna contra la mentira, la coacción moral, el fariseísmo y el sistema establecido. En Primera memoria, Ana María Matute presenta a Matia como protagonista, relatando los hechos desde su punto de vista y confiriendo a la historia un cierto valor testimonial, de cosa vivida. Se trata de una joven desde su infancia hasta la adolescencia, y como a través de esta etapa, va descubriendo los disimulos, hipocresías y formalidades de los mayores.

En Primera memoria toda esa vida de ensueño desaparecerá al ceder a la presión del tiempo y de las circunstancias ambientales en las que vive la chica. En esta última narración, nos aproximamos de nuevo al contorno trágico de los seres desilusionados de la escritora catalana, de los niños que se transforman de seres rebeldes a seres pasivos, vacíos, incapaces de rebelarse contra la injusticia del ambiente. Matia se encuentra que tiene que luchar entre dos mundos, el de sus parientes, colmado de restricciones y de hipocresía, y su propio universo, abierto a nuevos caminos y anclado en la infancia, y por consiguiente, en la inocencia. La novela refleja así la rebelión frustrada de la adolescente, el descubrimiento gradual de la falsedad del mundo adulto y, finalmente, la incorporación a este ambiente de opresión y restricciones. De esta manera, la joven se convierte en víctima, pues la sociedad caótica de la posguerra le trunca la posibilidad de una infancia normal, convirtiéndose en imitadora de la crueldad que advierte en los adultos.

9 Según Nanette Pascal: «Matia se ha transformado de niña rebelde a ser pasivo, vacío, incapaz de rebelarse contra la injusticia. Del desencanto ha pasado a la conforme aceptación» (Pascal, 1980: 73). 


\section{BIBLIOGRAFÍA}

Alvar, C. (1997): Breve historia de la Literatura española. Madrid: Alianza Editorial.

Cabedo, G. (2005): «La madre ausente. Inconformismo social en algunas novelas de la posguerra escritas por tres autoras españolas: Carmen Laforet, Carmen Martín Gaite y Ana María Matute». En: Cuadernos Lazarillo, 29, 57-61.

Curuchet, J. C. (1964): Introducción a la novela española de posguerra. Montevideo: Editorial Alfa.

Diáz, J. (1971): Ana María Matute. New York: Twayne Publishers.

Estébanez Calderón, D. (1999): Diccionario de términos literarios. Madrid: Alianza Editorial.

Ferrer, J. (2002): Historia de la literatura universal. Barcelona: Editorial Optima.

Galdona Pérez, R. I. (2001): Discurso femenino en la novela española de posguerra: Carmen Laforet, Ana María Matute y Elena Quiroga. Santa Cruz de Tenerife: Servicio de Publicaciones de la Universidad de la Laguna.

García Viñó, M. (1971): Novela española de posguerra. Madrid: Publicaciones Españolas.

Guillermo, E. (1971): Novelística española de los sesenta. New York: Eliseo Torres and Sons.

Jones, M. (1993): «Deciphering Silence in the Works of Ana María Matute». En: The Literary World of Ana María Matute. Coral Gables, Iberian Studies Institute, 19-26.

Martínez Cachero, J. M. (1995): Historia de la literatura Española. Siglos XVIII, XIX y XX. León: Editorial Everest.

Martínez Cachero, J. M. (1997): La novela española entre 1936 y el fin de siglo. Madrid: Editorial Castalia.

Matute, A. M. (1961): A la mitad del camino. Barcelona: Ediciones Rocas.

Matute, A. M. (1988): Fiesta al noroeste. José Más (ed.). Madrid: Cátedra.

Matute, A. M. (1959): Primera Memoria. Barcelona: Destino.

Pascal, N. (1980): El niño y sus circunstancias en las novelas de Ana María Matute. Guatemala: Cultural Centroamericana.

Pedraza Jiménez, F. (1997): Las épocas de la literatura española. Barcelona: Editorial Ariel.

Prieto, C. (2004): «El rechazo y distanciamiento de las estéticas del canon franquista y una perspectiva bajtiniana». En: Hispania, 87, 4, 682-691.

Soberano-Morán, A. (1989): «Ironía y parodia en Recuento de Luis Goytisolo: Crítica y destrucción de la España de posguerra». En: Hispania, 72, 3, 510-515.

Sotelo Vázquez, M. (1999): «Primera Memoria de Ana María Matute: La vida es una infancia repetida». En: Salina. Revista de Lletres, 13, 171-178.

Valera Ruzafa, A. (2003): «Un paso hacia la madurez lectora: análisis de dos cuentos de Ana María Matute». En: Didáctica (lengua y literatura), 15, 255-269.

Valis, N. (1982): «La Literatura Infantil de Ana María Matute». En: Cuadernos Hispanoamericanos, 389, 407-415. 


\section{NESREČNA OTROŠTVA V ROMANU PRIMERA MEMORIA ANE MARÍE MATUTE}

Ključne besede: Ana María Matute, otroštvo, odrasli, hinavščina

Delo Ane Maríe Matute je polno otrok, oseb, ki od nežnega otroštva trpijo pomanjkanje starševske ljubezni, živijo v krutem in sebičnem svetu, temelječem na hinavščini in nasilju, ki sta prežemala Španijo v povojnem obdobju. Roman Primera memoria [Prvi spomin] deluje kot Bildungsroman ali vzgojnostni roman, v katerem glavna junakinja razvija svojo osebnost v ključnem obdobju, ki sega od mladostništva do zrelosti. Matia v zgodbi pokaže svoj nekonformizem, ko v iskanju drugačnega sveta beži od zlaganosti odraslih v svet domišljije. Ana María Matute prikaže, kako junakinja postane žrtev kaotične povojne družbe in kako ne bo mogla premagati zatiralskega ozračja, temveč mu bo morala resignirano podleči. Prav takrat, ko se deklica zave nemožnosti situacije, dejansko izgubi nedolžnost otroštva in postane del sveta odraslih. Zadnje strani romana potrjujejo brezupen poraz junakinje, ko sprejme konvencionalnosti odraslih, vse laži in hinavščino, ki jih je na začetku sovražila. 